\title{
Correction to: HUWE1 controls MCL1 stability to unleash AMBRA1-induced mitophagy
}

\author{
Flavie Strappazzon $\mathbb{D}^{1}$ - Anthea Di Rita ${ }^{1,2}$ - Angelo Peschiaroli ${ }^{3}$ - Pier Paolo Leoncini ${ }^{4}$ - Franco Locatelli ${ }^{4,5}$. \\ Gerry Melino ${ }^{6,7} \cdot$ Francesco Cecconi $\mathbb{D}^{2,8,9}$
}

Published online: 30 October 2019

(c) The Author(s), under exclusive licence to ADMC Associazione Differenziamento e Morte Cellulare 2019

\section{Correction to: Cell Death \& Differentiation}

$$
\text { https://doi.org/10.1038/s41418-019-0404-8 }
$$

Since the publication of this article the authors have noted that there was an error in Figure 5.
The corrected image is supplied below. The authors apologize for any inconvenience this may have caused the readers.

The PDF and HTML versions of the paper have been modified accordingly.
Flavie Strappazzon

f.strappazzon@hsantalucia.it

$\triangle$ Francesco Cecconi cecconi@cancer.dk

1 IRCCS Fondazione Santa Lucia, 00143 Rome, Italy

2 Department of Biology, University of Rome Tor Vergata, 00133 Rome, Italy

3 National Research Council of Italy (CNR) Institute of Translational Pharmacology, IFT, Via Fosso del Cavaliere 100, 00133 Rome, Italy

4 Department of Paediatric Oncohematology and Cell and Gene therapy, IRCCS Ospedale pediatrico Bambino Gesù, 00143

Rome, Italy

5 Department of Gynecology/Obstetrics and Pediatrics, Sapienza University, Rome, Italy

6 Department of Experimental Medicine, TOR, University of Rome Tor Vergata, 00133 Rome, Italy

7 MRC Toxicology Unit, University of Cambridge, Cambridge, UK

8 Unit of Cell Stress and Survival, Center for Autophagy, Recycling and Disease (CARD), Danish Cancer Society Research Center, 2100 Copenhagen, Denmark

9 Department of Pediatric Hematology and Oncology, IRCCS Bambino Gesù Children's Hospital, Rome, Italy 
b

a

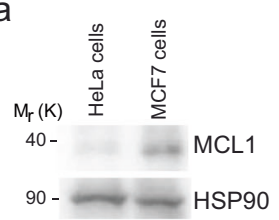

MCL1

AMBRA1 ActA Magnification 3X
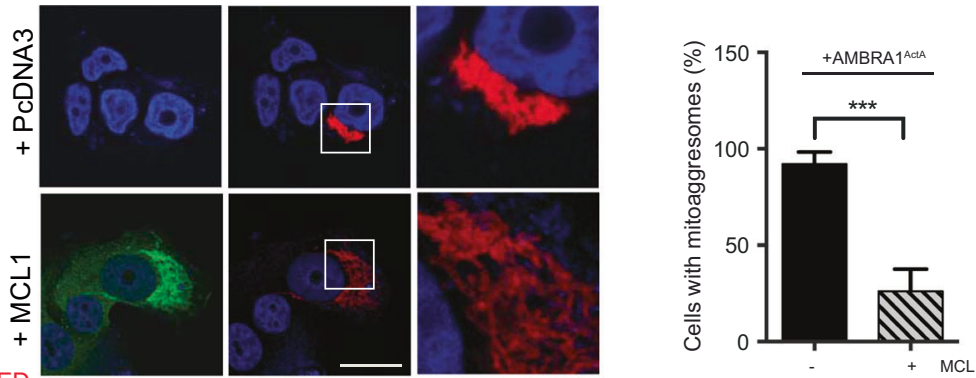

C

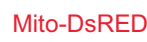

Ubiquitin
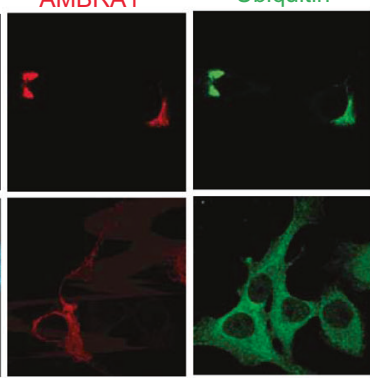

Merge

Magnification $4 X$
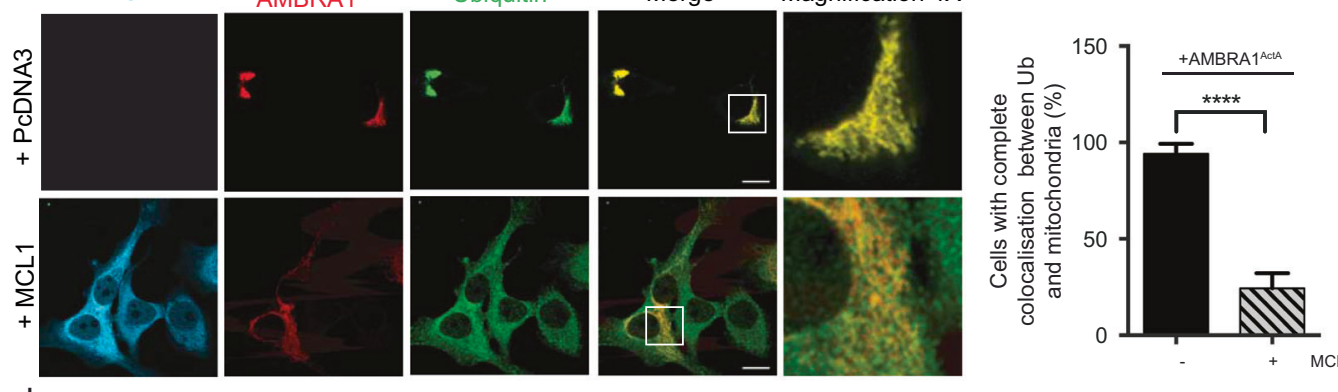

d
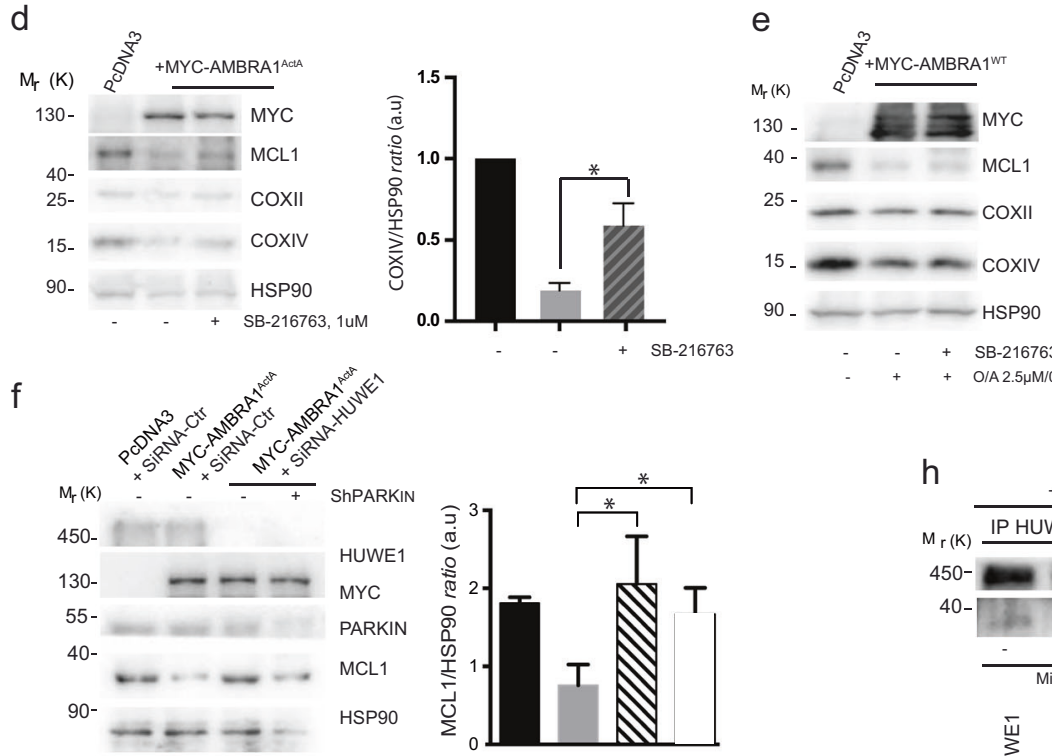

g
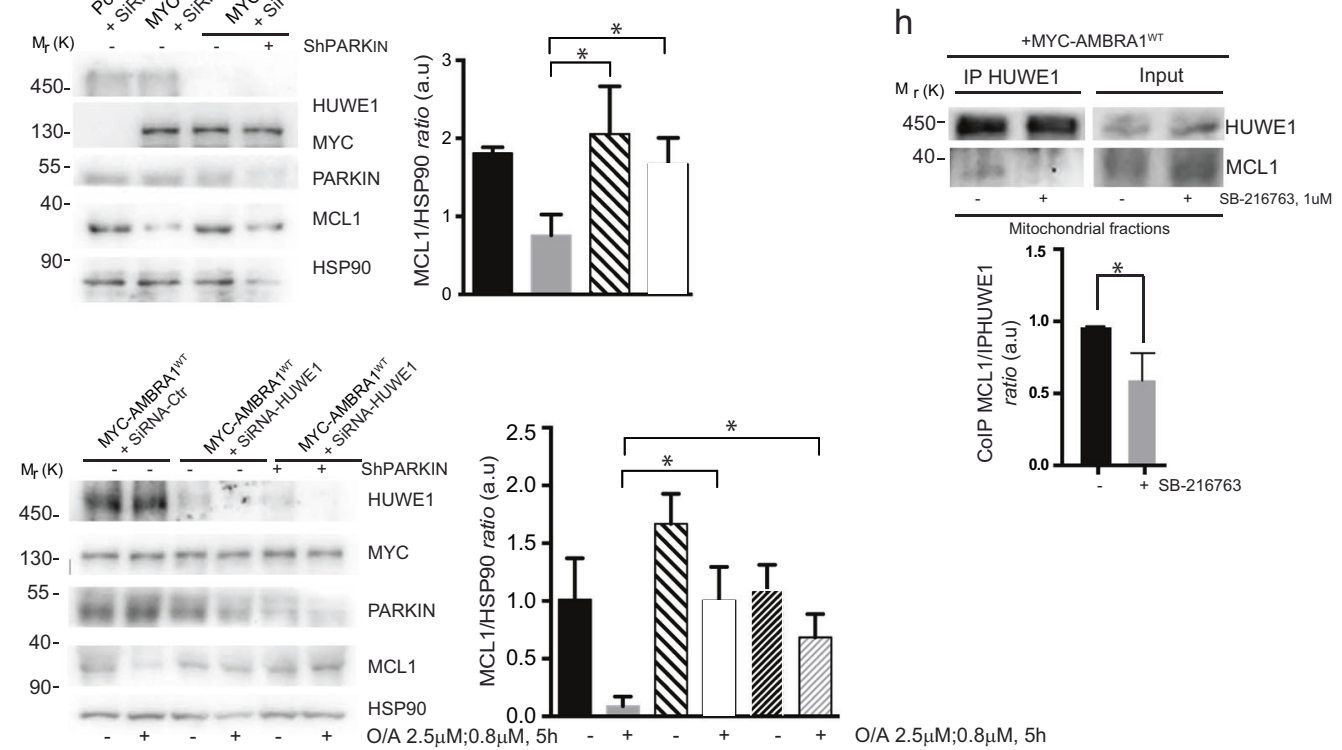

Fig. 5 